\title{
Analysis of vehicles complex displacement in the process of investigation of vehicle crash
}

\author{
Ivan Novikov ${ }^{1, *}$, Andrey Degtyar ${ }^{1}$, Dmitriy Lazarev ${ }^{1}$, and Vitaliy Makhonin ${ }^{2}$ \\ ${ }^{1}$ Belgorod State Technological University named after V.G. Shoukhov, Belgorod, Russia \\ ${ }^{2}$ Orel State University named after I.S. Turgenev, Orel, Russia
}

\begin{abstract}
Annotation. Nowadays, the vehicle crashes are the main problem concerned with automobilization growth, apart traffic management issues. The process of investigation of vehicle crash is an important task. There is very often the necessity to determine the vehicle crash mechanical device at each of its stages in order to determine the extent of responsibility of its participants, in the process of investigation of vehicle crash. However, it is not always possible due to the absence or efficiency of track conditions, on which the modern analysis models are currently based. The acquisition of general and inclusive model for vehicle displacement in the vehicle crash is the main task nowadays. The proposed model makes it possible to predict the vehicle displacement based on complex array of variables, at each mechanism's stage during the compound motion based on the fundamental principles of engineering (theoretical) mechanics.
\end{abstract}

Nowadays, in modern autotechnical studies related to investigation of vehicle crashes, the main problem is the absence of analysis consistency of vehicle displacement from the initial stage of dangerous situation until the end of the vehicle crash [1]. The problem is increased by the absence of ability to predict the complex vehicle displacement in an uncontrollable condition after meridian phase of accident due to simplification of analysis consistency, its averaging as well as its disintegration within individual parts of mechanism as a whole and at the level of its individual stages in particular [2]. The construction of comprehensive model of vehicle displacement with all its mechanical features, road conditions, confunction specificity in meridian phase of the accident and the inertial displacement as a result (of it) until the end of vehicle crash, is the current problem nowadays [3].

We will assume that, before the confunction, the body movement is plane and translational. The bodies velocities $\mathbf{V}_{\mathbf{1}}$ and $\mathbf{V}_{\mathbf{2}}$, directed along the reference axis, form an angle $\beta$ with each other. The working line of impact pulse makes an angle $\alpha$ with axis of the initial body at confunction (Figure 1).

The body masses will be denoted by $m_{1}$ and $m_{2}$. Moments of inertia of bodies relative to the central axes perpendicular to the plane of motion and passing through the centers of mass $J_{1}$ and $J_{2}[4]$.

\footnotetext{
*Corresponding author: ooows@mail.ru
} 


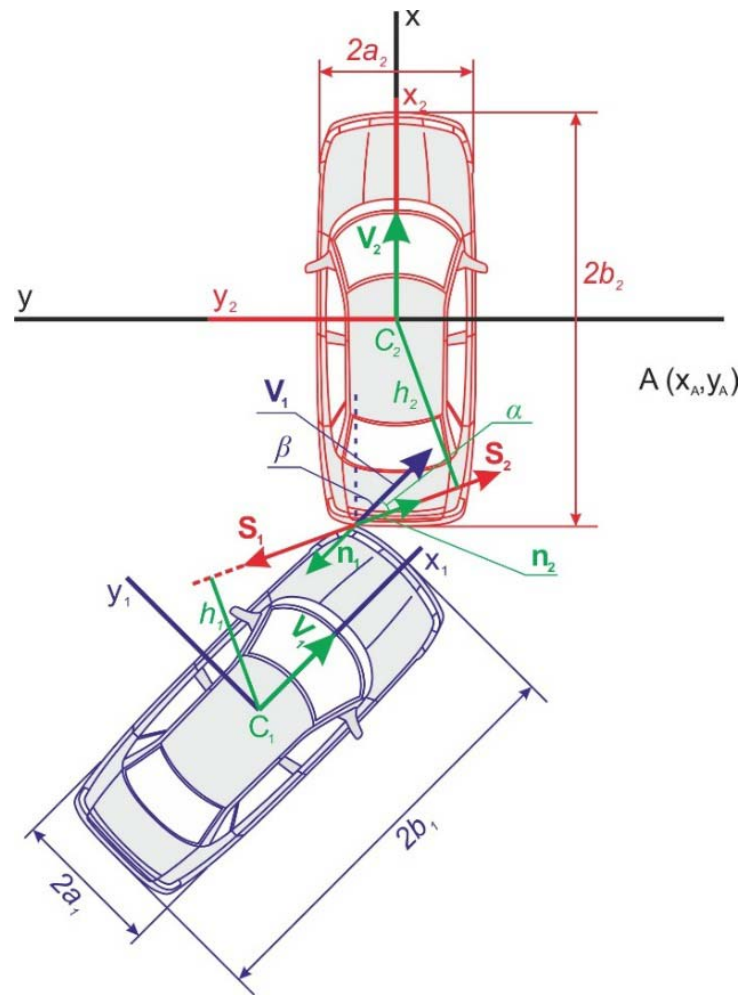

Fig. 1. The analytical model of impact of two vehicles.

We'll regard that both bodies (objects) have planes of material balance, which move in a common fixed plane. Impact momentum are located in the same plane.

Vectors $\mathbf{r}_{\mathbf{i}} \times \mathbf{n}_{\mathbf{i}}, \boldsymbol{\omega}_{\mathbf{i}}$ и $\boldsymbol{\Omega}_{\mathbf{i}}$ are perpendicular to the motion plane [5].

$$
G=\frac{m_{1}+m_{2}}{m_{1} \cdot m_{2}}+\frac{h_{1}^{2}}{J_{1}}+\frac{h_{2}^{2}}{J_{2}},
$$

where: $h_{1}$ and $h_{2}$ are level arms of impulses.

The level arms of impulses are defined through the coordinates of the impact point, while $h_{1}$ is expressed by coordinates of the impact point of body (object) 1 into the system of relative coordinates at point $\mathrm{C}_{1}$, and $h_{2}$ - into the system of relative coordinates at point $\mathrm{C}_{2}$ [6-7].

$$
\begin{gathered}
\left\{\begin{array}{l}
h_{1}=x_{1} \cdot \cos \left(90^{\circ}-\alpha\right)-y_{1} \cdot \cos \left(180^{\circ}-\alpha\right) \\
h_{2}=x_{2} \cdot \cos \left(90^{\circ}+\alpha+\beta\right)-y_{2} \cdot \cos (\alpha+\beta)
\end{array}\right. \\
\left\{\begin{array}{l}
h_{1}=x_{1} \cdot \sin \alpha-y_{1} \cdot(-\cos \alpha) \\
h_{2}=x_{2} \cdot[-\sin (\alpha+\beta)]-y_{2} \cdot \cos (\alpha+\beta)
\end{array}\right. \\
\left\{\begin{array}{l}
h_{1}=x_{1} \cdot \sin \alpha-y_{1} \cdot \cos \alpha \\
h_{2}=-x_{2} \cdot \sin (\alpha+\beta)-y_{2} \cdot \cos (\alpha+\beta)
\end{array}\right.
\end{gathered}
$$


We will take the moments of body inertia (momentas) as for rectangular solid in connection with axis which is perpendicular to the common fixed plane.

$$
\left\{\begin{array}{l}
J_{1}=\frac{m_{1}}{3} \cdot\left(a_{1}^{2}+b_{1}^{2}\right) \\
J_{2}=\frac{m_{2}}{3} \cdot\left(a_{2}^{2}+b_{2}^{2}\right)
\end{array}\right.
$$

The value $G$ is

$$
G=\frac{m_{1}+m_{2}}{m_{1} \cdot m_{2}}+\frac{3 \cdot\left(x_{1} \cdot \sin \alpha-y_{1} \cdot \cos \alpha\right)^{2}}{m_{1} \cdot\left(a_{1}^{2}+b_{1}^{2}\right)}+\frac{3 \cdot\left[-x_{2} \cdot \sin (\alpha+\beta)-y_{2} \cdot \cos (\alpha+\beta)\right]^{2}}{m_{2} \cdot\left(a_{2}^{2}+b_{2}^{2}\right)}
$$

Since the bodies (objects) move translationally before the interaction, then $U_{1}=V_{1} ; U_{2}=$ $V_{2}$, where: $U_{1}, U_{2}$ are body (object) velocities before impact $[8,9]$.

Let's find the speed projection components of velocities at the responding standards.

$$
\left\{\begin{array}{l}
\mathbf{U}_{1} \cdot \mathbf{n}_{1}=-V_{1} \cdot \cos \alpha \\
\mathbf{U}_{\mathbf{2}} \cdot \mathbf{n}_{2}=V_{2} \cdot \cos (\alpha+\beta)
\end{array}\right.
$$

We'll find an impact pulse

$$
\mathbf{S}=-\frac{1+\varepsilon}{G} \cdot\left(\mathbf{U}_{\mathbf{1}} \cdot \mathbf{n}_{\mathbf{1}}+\mathbf{U}_{\mathbf{2}} \cdot \mathbf{n}_{\mathbf{2}}\right),
$$

where: $\varepsilon$ is the recovery factor.

$$
S=\frac{1+\varepsilon}{G} \cdot\left[V_{1} \cdot \cos \alpha-V_{2} \cdot \cos (\alpha+\beta)\right]
$$

Determine the center-of-mass velocities after impact:

$$
\begin{gathered}
V_{1 x}=V_{1} \cdot \cos \beta-\frac{S}{m_{1}} \cdot \cos (\alpha+\beta) \\
V_{1 y}=-V_{1} \cdot \sin \beta+\frac{S}{m_{1}} \cdot \sin (\alpha+\beta) \\
V_{2 x}=V_{2}+\frac{S}{m_{2}} \cdot \cos (\alpha+\beta) \\
V_{2 y}=-\frac{S}{m_{2}} \cdot \sin (\alpha+\beta)
\end{gathered}
$$

Since the bodies (objects) were moving forward before the impact, then $\omega_{1 \mathrm{z}}=\omega_{2 \mathrm{z}}=0$. Determine rotational speeds (rates) of the bodies (objects) after impact

$$
\Omega_{1 z}=\frac{S \cdot h_{1}}{J_{1}} ; \quad \Omega_{2 z}=\frac{S \cdot h_{2}}{J_{2}}
$$

Let's consider the determined dependencies using a particular example. The vehicle «GAZ 322133» with 5 passengers in it and «Mercedes Benz 280 GE» as well as a «Freightliner GL120 COLUMBIA» with «Schwarzmüller KIS 3/E» full-trailer parked on the 
carriageway in a vehicle crash on the carriageway of Magistralniy proezd in Kursk. As a result of this vehicle crash, the passengers of public taxi bus died on accident scene because of received bodily injury, and the driver of public taxi bus was taken to health care center in Kursk with injuries of various degrees of severity (Figure 2-3).
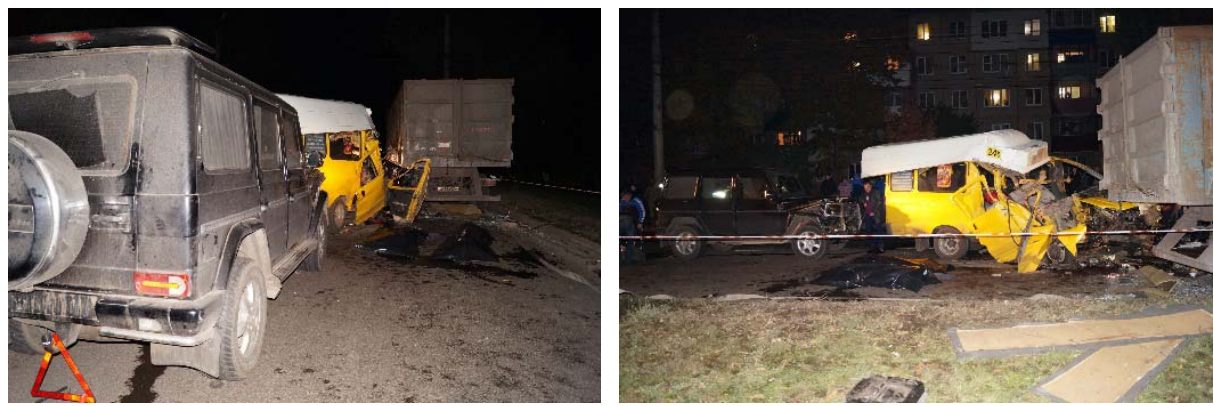

Fig. 2-3. Photographs from the accident scene.

As a result of vehicles' damage survey was determined that the initial contact was between the right forebody section of the vehicle «GAZ 322133» and the left hand rear part of «Schwarzmüller KIS 3/E» full - trailer (the overlap area was 0.2 meters), with that the vehicle «GAZ 322133» turned around at about $12^{\circ}(0.21$ radian $)$ and made the recontact with «Mercedes Benz $280 \mathrm{GE}$ ». Besides, according to the responses of electronic speedometer of the vehicle «GAZ 322133», was determined that the vehicle, at the moment of the contact, outpaced $80 \mathrm{~km} / \mathrm{h}$ (Figure 4 ).



Fig. 4. The view of the vehicle «GAZ 322133» mileometer reading.

The expert was faced with the problem of determining the turnaround time of the vehicle «GAZ 322133» in order to determine whether the driver of the vehicle «Mercedes Benz 280 GE» had a technical capability to prevent recontact .

The fonts for analysis are presented in table 1 .

Table 1. The fonts for analysis.

\begin{tabular}{|c|c|c|c|c|c|}
\hline$V_{1}$ & $V_{2}$ & $f$ & $\varepsilon$ & $\alpha$ & $\beta$ \\
\hline $80 \mathrm{~km} / \mathrm{h}$ & $0 \mathrm{~km} / \mathrm{h}$ & 0,7 & 0,3 & $5^{\circ}$ & $0^{\circ}$ \\
\hline \multicolumn{6}{|c|}{} \\
\hline $2 a_{1}$ & $2 b_{1}$ & $2 a_{2}$ & $2 b_{2}$ & $m_{1}$ & $m_{2}$ \\
\hline $1,7 \mathrm{~m}$ & $5,54 \mathrm{~m}$ & $2,55 \mathrm{~m}$ & $13,845 \mathrm{~m}$ & $3,5 \mathrm{t}$ & $39 \mathrm{t}$ \\
\hline
\end{tabular}

The analytical force model is presented in Figure 5. 


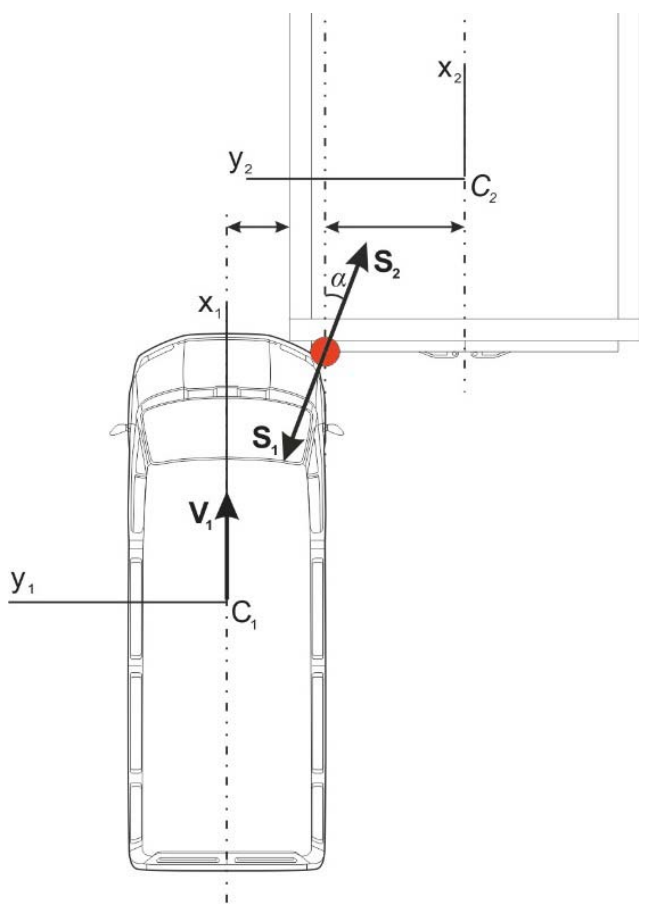

Fig. 5. The analytical model of impact of two vehicles from the example.

Thereinafter, we calculate, according to the model represented above, and obtain the following values in table 2 .

Table 2. The obtained values of analysis.

\begin{tabular}{|c|c|c|c|c|c|}
\hline$J_{1}$ & $J_{2}$ & $G$ & $S$ & $V_{1 \mathrm{x}}$ & $V_{1 \mathrm{y}}$ \\
\hline $\begin{array}{c}9794,63 \\
\mathrm{~kg} \cdot \mathrm{m}^{2}\end{array}$ & $\begin{array}{c}644106,21 \\
\mathrm{~kg} \cdot \mathrm{m}^{2}\end{array}$ & $0,6 \cdot 10^{-3}$ & $47,9 \cdot 10^{-3} \mathrm{~N} \cdot \mathrm{s}$ & $8,6 \mathrm{~m} / \mathrm{s}$ & $1,19 \mathrm{~m} / \mathrm{s}$ \\
\hline \multicolumn{5}{|c|}{} \\
\hline$V_{2 \mathrm{x}}$ & $V_{2 \mathrm{y}}$ & $h_{1}$ & $h_{2}$ & $\Omega_{1 \mathrm{z}}$ & $\Omega_{2 \mathrm{z}}$ \\
\hline $1,22 \mathrm{~m} / \mathrm{s}$ & $0,12 \mathrm{~m} / \mathrm{s}$ & $0,89 \mathrm{~m}$ & $1,6 \mathrm{~m}$ & $4,35 \mathrm{rad} / \mathrm{s}$ & $0,12 \mathrm{rad} / \mathrm{s}$ \\
\hline
\end{tabular}

Let's consider the further displacement of the first body. We will assume that it performs a plane motion. Let's write down equations of the displacement (motion) [4-6, 10].

$$
\left\{\begin{array}{l}
m \cdot \frac{d x_{1 c}}{d t^{2}}=\sum F_{k x}^{e} \\
m \cdot \frac{d y_{1 c}}{d t^{2}}=\sum F_{k y}^{e} \\
J_{c} \cdot \frac{d \varphi}{d t^{2}}=2 M_{c} \cdot \mathbf{F}_{k}^{e}
\end{array}\right.
$$

Whereof we get the equations 


$$
\left\{\begin{array}{l}
x_{1}=-\frac{-5,8 \cdot t^{2}}{2}+V_{1 x} \cdot t \\
y_{1}=-\frac{-0,4 \cdot t^{2}}{2}+V_{1 y} \cdot t \\
\varphi_{1}=-\frac{5,8 \cdot t^{2}}{2}+\Omega_{1 z} \cdot t
\end{array}\right.
$$

As stated above, the taper angle of the vehicle «GAZ 322133» towards the contact point is about $12^{\circ}(0,21$ radian $)$. On the basis of this condition, using the third equation, we obtain that the turnaround time to recontact is 0,68 second.

Now we will determine the distance on which the vehicle back axle will be displaced during this time in order to compare with the actual position of the vehicle at the accident site. To do this, we will define the level arm of banking in simplified form (Figure 6). It is $h_{1}$ $=3,4$ meters.

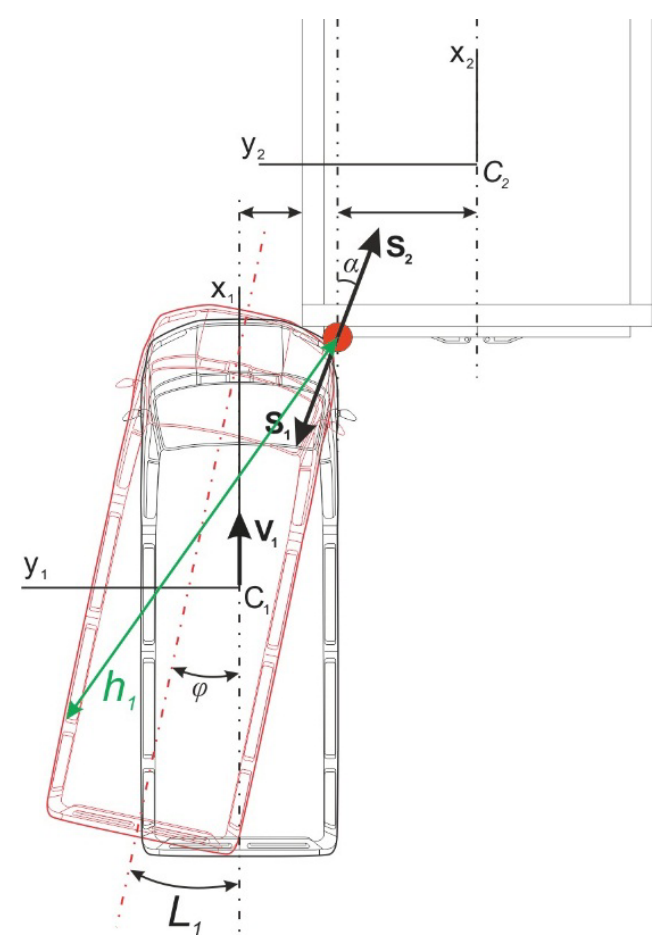

Fig. 6. The analytical model of impact of two vehicles from the example.

The distance dependence along the bow of displacement can be expressed through [11]:

$$
d L_{1}=h_{1} \cdot d \varphi \quad \text { whereof } \quad L_{1}=h_{1} \cdot \varphi
$$

Therefore we determine the distance $L_{1}$, which in this case will compose to 0,7 meters when the angle changes from $0^{\circ}$ to $12^{\circ}$, that is confirmed by the vehicle «GAZ 322133» final location on the roadway, stated in the case information of concerned accident (Figure 2).

Thus, the usage of proposed model allows to approach differentially to analysis of different situations, which connected with the complex displacement of vehicles as a result of their impact. The proposed method makes it possible to expand the array of design 
conditions of vehicles' displacement by vehicle crash through the infusion of additional font for analysis, for example, such as the wheels position relatively to the slip plain in the process of unsteered displacement, its rotation or blocking with consideration of different balance wheel and its influence on forecasting the explored displacement, as well as taking into different emergency responses (loss of part of the supporting wheels by impact, down draught displacement or displacement as a result of blocking one of the support points, etc.).

\section{References}

1. S.A. Evtiukov, Y.V. Vasilyev, Handbook on the examination of accidents, PH Petropolis, St. Petereburg (2015)

2. Y.B. Suvorov, Forensic road traffic examination. Forensic assessment of the actions of drivers and other persons responsible for ensuring road safety in accident areas: Educational assistance for universities, PH Examination, PH Law, Moscow, p. 208 (2004)

3. S. Evtiukov, M. Karelina, A. Terentyev, A method for multi-criteria evaluation of the complex safety characteristic of a road vehicle characteristic of a road vehicle. Transportation Research Procedia, v. 36, pp. 149-156 (2018)

4. S.M. Targ, Short course in theoretical mechanics, PH The higher school, Moscow, p. 415 (2007)

5. E. Rous, Rigid body dynamics. Tr. from English in 2 volumes. V. 1, PH Science, Moscow, p. 467 (1983)

6. A.A. Eichenwald, Theoretical Physics: General Mechanics, PH Librokom, Moscow, p. $328(2016)$

7. A.A. Eichenwald, Theoretical Physics: Solid State Mechanics, PH Librokom, Moscow, p. 224 (2011)

8. I.A. Novikov, D.A. Lazarev, Experimental Installation for Calculation of Road Adhesion Coefficient of Locked Car Wheel. Transportation Research Procedia, v. 20, pp 463467 (2017)

9. I.A. Novikov, D.A. Lazarev, D.V. Kudinov, The estimation of friction coefficient of vehicle's blocked wheel given with contact patch of the tread with the road surface, International Journal of Applied Engineering Research, v. 21, pp $42721-42724$ (2015)

10. M.G. Valishchev, A.A. Povzner, General Physics Course, PH Lan, Moscow, p. 576 (2010)

11. A.A. Yablonsky, V.M. Nikiforova, Course in theoretical mechanics. Educational assistance for universities, PH Integral Press, Moscow, p. 603 (2009) 